\title{
OBSERVATIONS OF THE BLUE JAY
}

JEAN BANCROFT, 306-200 Tuxedo Ave., Winnipeg, Manitoba. R3P OR3

As the Blue Jay is one of the most beautiful and interesting of birds, I have always been intrigued by it. But I had never been able to observe an entire nesting period of this bird until the summer of 1982.

In early June at our summer cottage at Whytewold on Lake Winnipeg, I noticed a pair of Blue jays endeavouring to snap off thin twigs from the hazelnut bushes. I had at one time seen a Blue Jay's nest with toilet paper hanging from beneath it; I subsequently hung some lengths on bushes in our yard. The attraction worked, and I was able to watch the direction in which the birds flew, and I found the nesting site about $60 \mathrm{~m}$ down the lane. The nest was built in the crotch of several vertical offshoots in a giant oak, approximately $6 \mathrm{~m}$ from the ground. It was difficult to see as it was concealed by twiglets and foliage.
In addition, my viewing was complicated by the fact that the tree stood directly in front of a cottage which had just become occupied. The nest was bulky but compact and was about 17 $\mathrm{cm}$ in outer diameter by $10 \mathrm{~cm}$ deep. According to Bent "the inner cup measures about $3 \frac{1}{2}$ to 4 " $(8.9 \mathrm{~cm}$ to $10.2 \mathrm{~cm}$ ) in diameter by $21 / 2 . "(6.4 \mathrm{~cm})$ in depth."'

I watched the birds carry many twigs, paper, rootlets, as well as moss, lichens and silken webs from the nest of a Least Flycatcher. (Much to my disgust, the jays pulled apart the flycatcher's nest which she was in the process of constructing.)

I was not able to determine the number of eggs in the nest but there are "usually 4 to 6 ; buffy to greenish or bluish with small spots and blotches of

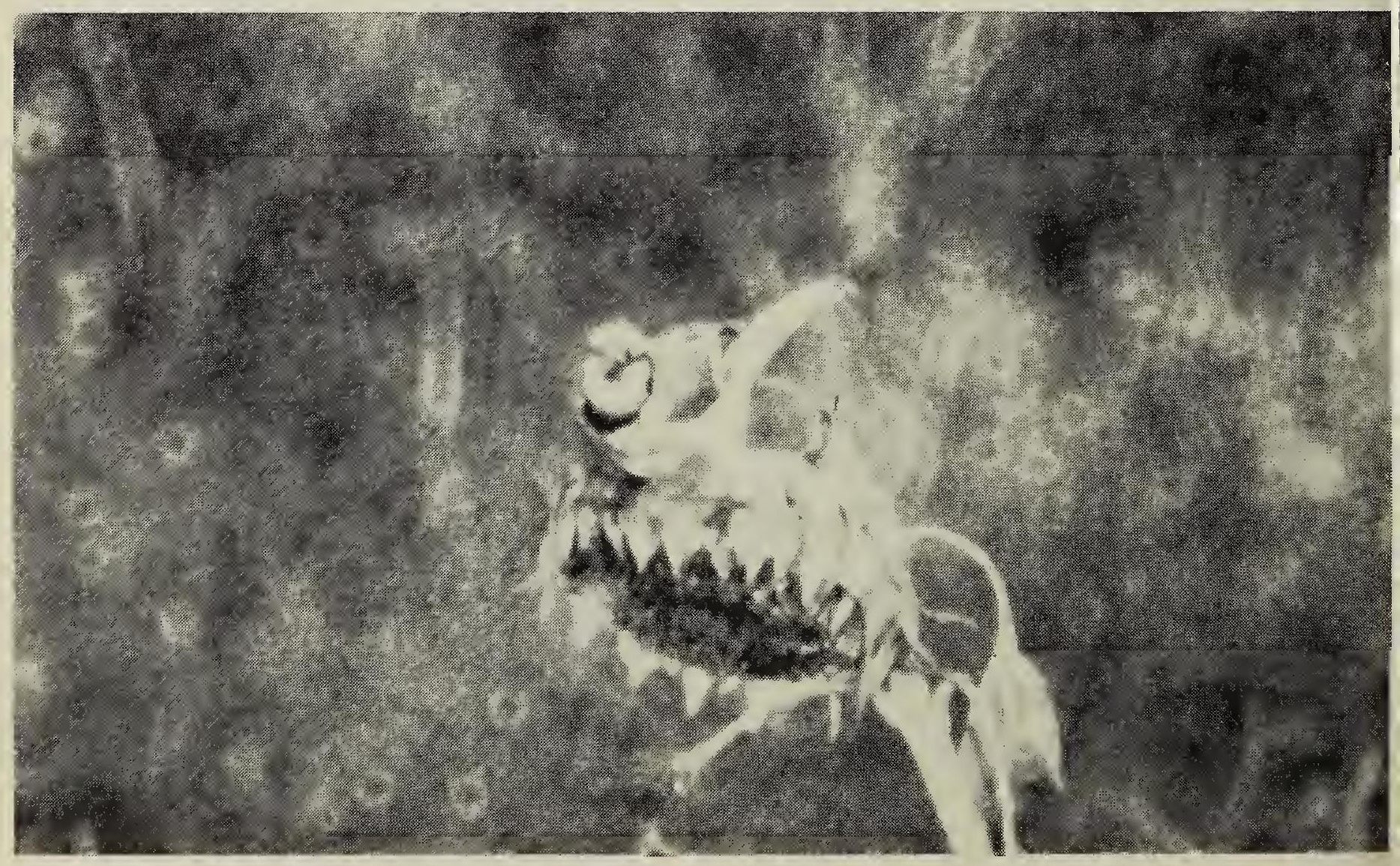


brown or olive. Incubation period is 17 to 18 days". " As the sexes are similar I was not able to ascertain if both took part in the incubation; Bent claims that they do, "each relieving the other at more or less regular intervals," but Colin Harrison says "incubation by female alone, fed by male."14

On 15 June I first noticed a bird sitting on the nest. I observed the nest on several occasions, and on the 26th both male and female flew away from the site. on the 27th they both came to our feeder and birdbath. While around the nesting site they had, up to this time, been very quiet, but on 1 July I heard the joyous yodelling call, "toowheeoodle, too-wheeoodle." In the early spring I had seen a jay using this call to serenade a female which was sitting on the upper branch of a tree with six other jays. The bird moved its whole ody up and down like a teeter-totter.

At the back of our yard on 8 July I heard a great cacophony from jays creaming and several smaller birds iving alarm calls. Because I had been bserving nearby nests of Red-eyed Vireos, Northern Orioles, and Tree swallows, I began to wonder if the jays ad predated any of these nests, as they were all fairly close together. Upon urrying outdoors I found a jay on the around tearing apart a nearly-fledged oung bird. I presumed it was a Redyed Vireo nestling because the vireos were in a dreadful state for at least two hours, calling incessantly. The jay must lave plucked all the young vireos from heir nest because, shortly thereafter it was empty. The jay finally flew to its nest with the remains of a nestling. A similar bservation is alluded to by Bent.

On 17 July an adult came to pick up read at our front feeder and it flew owards the nest site. Two days later I bserved three fair-sized nestlings beng fed. On several occasions, from 239 July, both adults flew around and in and out of surrounding trees, giving hlarm calls, "jay, jay, jay", and on 30
July the three fledglings were flying around the trees, shouting almost as loudly as their parents - a large gray squirrel was close at hand.

It was exciting to watch the parents and fledglings come to our feeder. The young ones were almost adult size except for their tails. They gave a perpetual repetitive squawking as they spread their wings and opened their beaks simultaneously. The parent picked up one sunflower seed at a time and placed it between its toes while it picked off the outer shell. Later on the hazelnuts and acorns received the same treatment. On several occasions I noticed an adult flew away with some food in its beak. This is quite a usual procedure, according to biologist and writer, John Dennis. In his book he further states "usually much more is tucked in an enlargement of the throat known as the craw or gullet."2

On 8 August I was delighted to find that there were two new fledglings, stubtailed, in the backyard bushes, making five in all. The whole family returned on 28 August to our front yard feeder. Above all, it was delightful to see the whole family at the birdbath taking turns splashing about. A similar incident is reported in Bent.

During the time that the jays were coming to the feeder, there was an Eastern Wood Pewee tending her little brood in a nest approximately $6 \mathrm{~m}$. from the ground in an old oak tree close by. Both male and female pewees expressed great apprehension on numerous occasions and they gave the jays quite a difficult time by performing aerial dives and attacking the jays' heads. Also a pair of House Wrens was kept on the alert when frequently a jay flew with food to a branch close to the one from which the wrens' nest-box was hanging; there were many alarm calls all round.

When the jays came to the feeder (always sounding their harsh alarm calls) other birds disappeared. As John 
Dennis poinis out, "this is a ruse that usually clears out the competition and gives jays free access to the food." His observations also indicate that "the role of jays as sentinels was especially apparent. ... There can be no doubt that jays exert an influence on the bird community far beyond their numbers. Their alarm notes both save lives and cause confusion. This is true not only at the feeding station but also in the wild."

As Blue Jays can frequently be seen all winter in Winnipeg and Whytewold, maybe our family of jays will not migrate either, but will choose to seek shelter in a giant spruce tree. At any rate, it is hoped that a pair will nest again in th vicinity of our cottage in the summer o 1983.

BENT, C. 1946. Life histories of Nortt American jays, crows and titmice Bulletin 191, Smithsonian Institution Washington.

${ }^{2}$ DENNIS, J. V. Beyond the bird feeder. A A. Knopf, Inc.

${ }^{3}$ GODFREY, W. E. 1966. The birds o Canada. National Mus. Canada Bull 203, Queen's Printer, Ottawa.

${ }^{4}$ HARRISON, COLIN. 1978. A field guide to the nests, eggs and nestlings of North American birds. Collins, London.

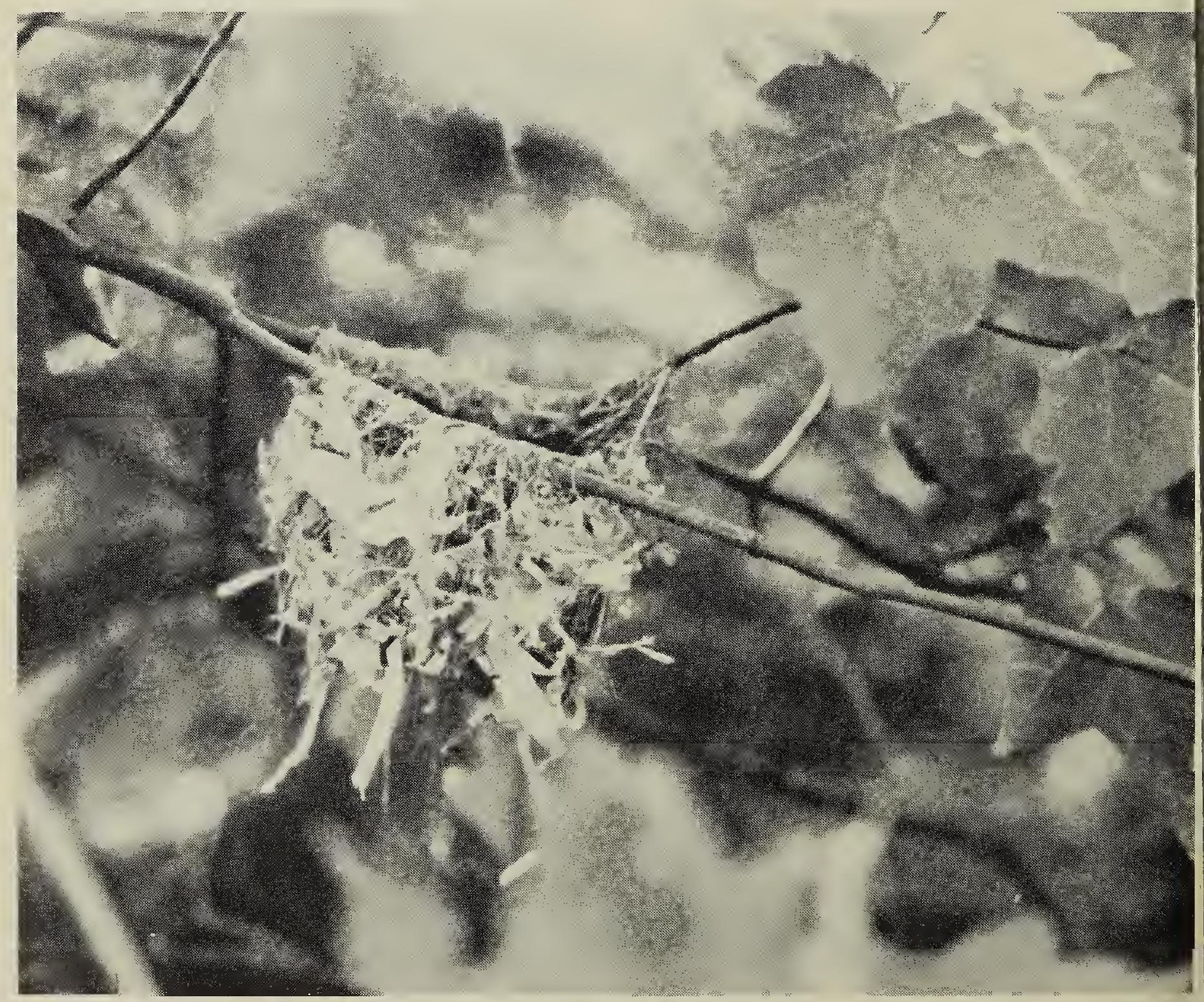

